Erratum

\title{
Light-induced expression of ipt from Agrobacterium tumefaciens results in cytokinin accumulation and osmotic stress symptoms in transgenic tobacco
}

John C. Thomas ${ }^{1,3, *}$ Ann C. Smigocki ${ }^{2}$ and Hans J. Bohnert ${ }^{1}$

${ }^{1}$ Departments of Biochemistry and of Plant Sciences, The University of Arizona, Tucson, AZ 85721, USA $;^{2}$ Plant Molecular Biology Laboratory, PSI, USDA/ARS Beltsville, MD 20705, USA; ${ }^{3}$ present address: Department of Natural Sciences, University of Michigan-Dearborn, Dearborn, MI 48128-491 (*author for correspondence)

Plant Molecular Biology 27: 225-235, 1995

On page 229, in the first paragraph of the second column, a mistake has occurred. The correct units are $\mathrm{pmol} / \mathrm{mg}$ dry weight instead of $\mathrm{pmol} / \mathrm{g}$ fresh weight. 